Journal Of Polymers And The Environment

December 2015, Volume 23 Issue 4 Pages 493-505

http://dx.doi.org/10.1007/s10924-015-0736-5

http://archimer.ifremer.fr/doc/00296/40735/

(c) Springer Science+Business Media New York 2015

\title{
Natural Degradation and Biodegradation of Poly(3- Hydroxybutyrate-co-3-Hydroxyvalerate) in Liquid and Solid Marine Environments
}

\author{
Deroine Morgan ${ }^{1,2,3}$, César Guy ${ }^{2}$, Le Duigou Antoine ${ }^{1}$, Davies Peter ${ }^{3}$, Bruzaud Stéphane 1, * \\ ${ }^{1}$ Univ Bretagne Sud, EA 4250, LIMATB, F-56100 Lorient, France. \\ ${ }^{2}$ Univ Bretagne Sud, SERPBIO, F-56321 Lorient, France. \\ ${ }^{3}$ IFREMER, Marine Struct Grp, Ctr Bretagne, F-29280 Plouzane, France. \\ *Corresponding author : Stéphane Bruzaud, email address : stephane.bruzaud@univ-ubs.fr
}

\begin{abstract}
:
In this study, natural degradation and biodegradation of poly(3-hydroxybuyrate-co-3-hydroxyvalerate) (PHBV) films were followed in different marine environments. First of all, ageing of PHBV films was investigated in natural seawater for 180 days and degradation was followed by means of weight loss measurements, scanning electron microscopy (SEM), differential scanning calorimetry and steric exclusion chromatography. In a second part, biodegradation tests were performed on PHBV powder, by following carbon dioxide (CO2) release(,) to highlight the PHBV bioassimilation of marine microorganisms. Three different marine environments were considered for biodegradation tests: a solid inoculum with foreshore sand, a solid-liquid inoculum with sand and seawater and a liquid inoculum with seawater. In the latter, a biofilm was added to study the influence of microorganisms on biodegradation kinetics. The films aged under natural conditions show a large loss of weight after 180 days in immersion, around $36 \%$, confirmed by SEM pictures which show an increase of the surface erosion and a decrease of the sample thickness. Microorganisms' attack occurred as suggested by $\mathrm{CO} 2$ release during biodegradation tests, whatever the environment studied.
\end{abstract}

Keywords : PHBV, Natural ageing, Degradation, Biodegradation, Seawater 


\section{Introduction}

The large-scale accumulation of waste plastics in oceanic gyres is now well-known [1-3] and poses severe environmental pollution problems [4-6]. The plastics are mainly petroleumbased synthetic polymers [7,8] and are extremely resistant to microbial attack. Due to their high molecular mass, their stability or in some cases high numbers of aromatic rings [9], their estimated lifetime may be hundreds of years. To avoid this issue, the development of new polymers, bio-based and biodegradable, appears as a promising alternative solution. In particular, polyhydroxyalkanoates (PHA), which are microbial polyesters, have received considerable attention in the research community. PHAs are versatile polyesters produced by numerous bacterial species as intracellular storage compounds of carbon and energy. They have many other advantages like biocompatibility and thermoplastic processing capacity. Moreover, their mechanical properties are similar to various synthetic thermoplastics [10]. From an environmental point of view, the polymer biodegradability can be an added value as the waste management is always more complex. Indeed, biodegradation is a combination of physical, chemical and biological phenomena leading to the dissolution of material by enzymatic action of microorganisms. At the last stage, there is a reorganization of the biomass with a consumption of $\mathrm{O}_{2}$, a release of $\mathrm{CO}_{2}\left(\mathrm{CH}_{4}\right.$ in anaerobic conditions $), \mathrm{H}_{2} \mathrm{O}$, energy and a possible generation of new organic molecules which thus enable a close-loop. This is referred to as complete mineralization [8]. There are several methods to monitor biodegradation. One of the most commonly used in the literature is the monitoring of the weight loss of the samples, but this is a global approach and it is not directly related to biodegradation. Two other approaches, more quantitative, exist: the monitoring of oxygen consumption and the monitoring of $\mathrm{CO}_{2}$ emissions [11-13], the latter is used in this study.

In the literature, the biodegradability of PHA is generally studied in compost $[12,14,15]$, real environments like soil $[16,17]$ or river water $[18,19]$. Little attention has been devoted to the microorganism degradation (or biodegradation) in marine environments. In a previous paper [20], degradation of poly(3-hydroxybuyrate-co-3-hydroxyvalerate) (PHBV) with a large thickness $(4 \mathrm{~mm})$ in two marine environments (natural seawater and filtered and renewed seawater) was evaluated. Results highlighted a significant weight loss after one year of immersion for the PHBV samples in natural seawater but the biodegradation of the samples was not studied. 
The aims of this paper are, first, to present the natural ageing of a PHBV film (thickness 200 $\mu \mathrm{m})$ in a marine environment and, then to study the biodegradation of PHBV in different marine environment. Ageing of PHBV films in natural seawater was investigated over a period of 180 days and several physico-chemical analyses were carried out using gravimetry, scanning electron microscopy (SEM), differential scanning calorimetry (DSC) and steric exclusion chromatography (SEC). Then, PHBV biodegradation was followed by monitoring release of $\mathrm{CO}_{2}$ and three different marine environments were considered: a solid inoculum with foreshore sand, a solid-liquid inoculum with sand and seawater and a liquid inoculum with seawater.

\section{Experimental}

\subsection{Materials}

PHBV, with a molar ratio of HB to HV of 92:8 and commercialized in pellet form under the name ENMAT Y1000P, was supplied by Tianan Biological Materials Co. Ltd. (China). According to the manufacturer, this PHBV has the following properties: density $=1.25 \mathrm{~g} / \mathrm{cm}$, $\mathrm{T}_{\mathrm{g}} \approx 4^{\circ} \mathrm{C}, \mathrm{T}_{\mathrm{m}}=175^{\circ} \mathrm{C}$ and an average molecular weight $\bar{M}_{\mathrm{w}} \approx 400 \mathrm{~kg} \cdot \mathrm{mol}^{-1}$. This grade has been comprehensively characterized in a recent paper [21].

Cellulose (less than 20 microns thick) was used as a positive control material in the biodegradation tests. All chemicals products and reagents used in this study were analytical grade and were purchased from Sigma-Aldrich.

\subsection{Preparation of specimens}

\subsubsection{Film}

PHBV pellets were dried at $50^{\circ} \mathrm{C}$ under vacuum for $24 \mathrm{~h}$ before processing. For the preparation of film specimens, pellets were extruded in a single screw extruder (Brabender) at $50 \mathrm{rpm}$ with the following temperature profile: $165 / 180 / 180 / 180^{\circ} \mathrm{C}$ from the hopper to the die. Then, the film was calendered with a thickness of 200 microns. The films were cut to size 200 $\mathrm{x} 120 \mathrm{~mm}$ and placed in racks which were then immersed in seawater in order to follow chemical and physical properties. 


\subsubsection{Powder}

As recommended in most standards for biodegradation tests, the material used to evaluate the percentage of biodegradation was in the form of powder [22], as this allows a uniform mixture of the polymer in the media. To obtain a fine powder of PHBV, pieces of this polymer were frozen in liquid nitrogen and then ground using an ultracentrifuge mill. The powder sample was sieved through a $500 \mu \mathrm{m}$ mesh screen.

\subsubsection{Elemental analysis}

Elemental analysis has been performed to determine the percentage of carbon, hydrogen, oxygen and nitrogen in PHBV and cellulose materials. The amount of total organic carbon $\left(\mathrm{C}_{\mathrm{TOC}}\right)$ contained in the test material allows the theoretical amount of $\mathrm{CO}_{2}\left(\mathrm{mCO}_{2}\right.$ theoretical $)$ that can be produced by total oxidation of the tested material to be calculated using the following equation:

$\mathrm{m}_{\mathrm{CO}_{2} \text { theoretical }}=\mathrm{C}_{\mathrm{TOC}} \times \frac{44}{12} \times \mathrm{W}$

where $\mathrm{W}$ is the weight of the material sample $(\mathrm{g}), 44$ and 12 are the molar weight of $\mathrm{CO}_{2}$ and the atomic weight of carbon $(\mathrm{g} / \mathrm{mol})$, respectively. The value of $\mathrm{m}_{\mathrm{CO} 2}$ theoretical for the tested material was used to calculate its percentage of biodegradation $\left(\% \mathrm{CO}_{2}\right)$ during a biodegradation test. As a result of this test, the percentage of carbon in the PHBV is $54.9 \mathrm{wt} \%$ and in the reference (cellulose) $44 \mathrm{wt} \%$.

\subsection{Ageing conditions}

\subsubsection{Natural ageing}

Natural ageing tests were performed in the Lorient harbor (France) for six months and samples were placed in lantern nets. Characteristic parameters of Lorient seawater, from March 2012 to Sept 2012, are summarized in Table 1. Water temperature varied from 10.9 to $19.8^{\circ} \mathrm{C}$. Water $\mathrm{pH}$ was relatively constant around 8 during the study. Salinity and oxygen contained in the seawater were in the standard average range.

The mean number of colony-forming units (CFU) determined for seawater samples taken in the harbor was $17000 \mathrm{CFU} / \mathrm{mL}$. The bacterial contribution is an essential parameter for PHA biodegradation studies. A series of seawater dilutions was mixed with marine agar and incubated at $25^{\circ} \mathrm{C}$ for $24 \mathrm{~h}$. After the necessary incubation period, the colony counting was 
performed for each petri dish containing less than 300 colonies. The value in the initial seawater is obtained by taking into account the dilution ratio.

\subsubsection{Inoculum preparation in solid state}

The following procedure is an adaptation from the NF U52-001 (annexe F) standard [22]. To perform the biodegradation test in the solid phase, foreshore sand was taken from the Atlantic coast (Morbihan-France). Three compositions of inoculum were used. For the control sample, $30 \mathrm{~g}$ of sand was weighed accurately and placed in a polypropylene vial with a capacity of 60 $\mathrm{mL}$. The total bacterial count was estimated at $6.7010^{6} \mathrm{CFU}$ per millilitre of leachate, representative of about $1.2410^{6} \mathrm{CFU}$ per gram of wet sand. To prepare the reference sample containing the micronized cellulose and the analysed sample containing PHBV powder, 50 $\mathrm{mg}$ carbon equivalent were placed in the vial and added to $30 \mathrm{~g}$ of foreshore sand. The inoculums and the sample were mixed in order to optimise the contact surface.

To test the PHBV powder biodegradation, a glass jar, with a capacity of $1 \mathrm{~L}$ and a sealed closure contained three vials (Figure 1): one for the inoculum, one for the distilled water and another for the absorbing solution containing $20 \mathrm{~mL}$ of $\mathrm{NaOH}(0.2 \mathrm{~N})$. The operation was repeated 3 times. To conclude on the solid test, nine jars were used: three for the control (blank tests), three for the positive material (cellulose reference) and another three jars for the tested material (PHBV). After the jars had been hermetically closed, they were placed in incubation in an oven at $25^{\circ} \mathrm{C}$.

\subsubsection{Inoculum preparation in solid / liquid state}

The two following procedures are an adaptation of the Sturm test. To perform the test in the solid / liquid state, foreshore sand and seawater were taken from the Atlantic coast (Morbihan-France). The blank sample was prepared in the following way: $30 \mathrm{~g}$ of sand was weighed accurately and placed in a vial with a capacity of $250 \mathrm{~mL}$, and $100 \mathrm{~mL}$ of seawater was added. The operation was repeated 3 times. The total bacteria content was estimated at $3.6510^{5} \mathrm{CFU}$ per $\mathrm{mL}$ of the mixture.

To prepare the vial "cellulose reference" and the vial "tested material", the basic preparation was identical to the preparation of the control vial except that we added to the incubation medium $50 \mathrm{mg}$ carbon equivalent micronized cellulose for reference, and to the test sample PHBV finely ground as recommended for biodegradation tests. Each operation was also repeated 3 times. 
Each vial was connected to a second vial with the same capacity $(250 \mathrm{~mL})$ which contained the absorbing solution (Figure 2): $20 \mathrm{~mL}$ of a $\mathrm{NaOH}\left(0.2 \mathrm{~mol} . \mathrm{L}^{-1}\right)$ and $20 \mathrm{~mL}$ of distilled water. Airflow between the two vials was ensured by a sealed air pump. All the vials were then placed in a water bath at $25^{\circ} \mathrm{C}$.

\subsubsection{Inoculum preparation in liquid state}

The objective is this part was to understand the influence of bacterial concentration on the kinetics of biodegradation. In fact, depending of the kind of seawater, for example tropical mangrove or in seawater from ocean, the biodegradation conditions such as microorganism population or rate can hugely varied [19]. The preparation was similar to that of the solidliquid inoculum except that the foreshore sand was replaced by a defined amount of biofilm. Biofilm was actually collected on the walls of breeding fish tank. Two concentrations were studied: $5 \mathrm{~mL}$ and $50 \mathrm{~mL}$ of biofilm were placed in vials, $95 \mathrm{~mL}$ and $50 \mathrm{~mL}$ of natural seawater was added, and corresponded to a total amount of bacteria estimated at $1.3010^{5}$ $\mathrm{CFU} / \mathrm{mL}$ or 1.14 to $10^{6} \mathrm{CFU} / \mathrm{mL}$, respectively.

For these tests in the liquid state, 3 tests were performed, two for the different concentrations and one for the cellulose reference. The installation was the same as shown in figure 2 and incubation temperature was $25^{\circ} \mathrm{C}$.

\subsection{Characterization techniques}

\subsubsection{Weight Change}

Following weight changes is a useful method to characterize irreversible degradation. At selected immersion times, film specimens immersed in seawater were removed, washed with distilled water, wiped and weighted at room temperature $\left(23^{\circ} \mathrm{C}\right.$ and $\left.\mathrm{RH}=50 \%\right)$ on a weighting machine with a precision of $0.1 \mathrm{mg}$. The percentage loss, at any time $\mathrm{t}, \mathrm{WL}_{\mathrm{t}}$, was determined by Eq. (2):

$W L_{t}(\%)=\frac{W_{o}-W_{d}}{W_{o}} \times 100$ 
where $\mathrm{W}_{0}$ and $\mathrm{W}_{\mathrm{d}}$, indicate, respectively, initial weight of materials prior to water exposure and weight of dried material (after immersion). At least five specimens were tested after removal, and the results were averaged arithmetically.

\subsubsection{Scanning electron microscopy (SEM)}

Microscopy analyses were performed with a Jeol JSM 6460LV scanning electron microscope (SEM) to examine the surface and the fracture zone of the dry PHBV specimens. Prior to observation, the fracture surfaces of unaged and aged PHBV were prepared by breaking specimens in liquid nitrogen. Then, the specimens were sputter-coated with a thin gold layer by means of a sputtering apparatus (Edwards Sputter Coater) before examination.

\subsubsection{Thermal properties}

Differential Scanning Calorimetry (DSC) analysis was performed on samples of about $10 \mathrm{mg}$, in standard aluminium pans, using Mettler-Toledo DSC882 equipment under a nitrogen atmosphere. Data were recorded at a heating rate of $20^{\circ} \mathrm{C} / \mathrm{min}$. The samples were heated from 20 to $200^{\circ} \mathrm{C}$ and kept at $200^{\circ} \mathrm{C}$ for 3 minutes. They were then cooled to $-20^{\circ} \mathrm{C}$ and a second heating scan was performed from -20 to $200^{\circ} \mathrm{C}$ to distinguish the reversible effects from permanent changes. The degree of crystallinity was determined by Eq. (3):

$\chi=\frac{\Delta H_{m}}{\Delta H_{100 \%}}$

where $\Delta \mathrm{H}_{\mathrm{m}}\left(\mathrm{J} / \mathrm{g}\right.$ of polymer) are the melting enthalpy. $\Delta \mathrm{H}_{100 \%}$ is the melting enthalpy for PHBV of $100 \%$ crystallinity, taken to be $146 \mathrm{~J} / \mathrm{g}$ [23]. This value, found for PHB homopolymer by Barham et al. [11], is considered as a good approximation of the $\Delta \mathrm{H}_{100 \%}$ for PHBV samples, provided that the copolymers have a low percentage of hydroxyvalerate units.

\subsubsection{Molecular weight measurement}

Steric Exclusion Chromatography (SEC) was used to determine changes in molecular weight. The apparatus is equipped with a set of three columns: two ResiPore and one PL gel Mixed C (Polymer Labs.). The detection system is composed of a refractometer and a UV detector. Chloroform was used as eluent with a flow rate of $0.8 \mathrm{~mL} / \mathrm{min}$. The elution profiles were analysed by the Empower GPC module software (Waters). Calculations were based on 
calibration curves obtained from polystyrene standards ranging from $200 \mathrm{~g} / \mathrm{mol}$ up to $6 \times 106$ $\mathrm{g} / \mathrm{mol}$. The weight-average molecular weight $\left(\bar{M}_{\mathrm{w}}\right)$ and number-average molecular weight $\left(\bar{M}_{\mathrm{n}}\right)$ were obtained from the SEC analysis. The polydispersity index (PI) was calculated as $\bar{M}_{n} / \bar{M}_{n}$

\subsubsection{Description of the experimental biodegradation set-up}

The $\mathrm{CO}_{2}$ produced by microorganisms, in each jar, reacts with the absorbing solution of hydroxide sodium $(\mathrm{NaOH})$ at $0.2 \mathrm{~mol} . \mathrm{L}^{-1}$ to produce sodium carbonate $\left(\mathrm{Na}_{2} \mathrm{CO}_{3}\right)$ [13]:

$\mathrm{CO}_{2}+2 \mathrm{NaOH} \rightarrow \mathrm{Na}_{2} \mathrm{CO}_{3}+\mathrm{H}_{2} \mathrm{O}$

The sodium carbonate is precipitated as barium carbonate $\left(\mathrm{BaCO}_{3}\right)$ by $\mathrm{BaCl}_{2}$ solution, as shown below:

$\mathrm{Na}_{2} \mathrm{CO}_{3}+\mathrm{BaCl}_{2} \rightarrow 2 \mathrm{NaCl}+\mathrm{BaCO}_{3} \downarrow$

The amount of carbon dioxide produced was determined by titrating the remaining sodium hydroxide with $0.10 \mathrm{~mol} . \mathrm{L}^{-1}$ hydrochloric acid to thymolphthalein end-point.

$\mathrm{NaOH}+\mathrm{HCl} \rightarrow \mathrm{NaCl}+\mathrm{H}_{2} \mathrm{O}$

The sodium hydroxide traps were removed and titrated before their capacity was exceeded. At each removal of the absorbing solution, the vials were reweighed to check moisture loss and left open to fresh air before replacing the fresh vial of $\mathrm{NaOH}$ solution. Jars or vials were then resealed. Distilled water was added periodically into the medium in order to maintain the initial weight of the vial.

The percentage of biodegradation of the tested materials was determined by comparing the amount of $\mathrm{CO}_{2}$ released during its microbial degradation with the theoretical amount of $\mathrm{CO}_{2}$ $\left(\mathrm{mCO}_{2 \text { theoretical }}\right)$ that could be produced by the tested material, as shown in the equation below:

$\% \mathrm{CO}_{2}=\frac{\left(m_{\mathrm{CO}_{2} \text { test }}-m_{\mathrm{CO}_{2} \text { control }}\right) \times 100}{m_{\mathrm{CO}_{2} \text { theoretical }}}$

where $\mathrm{mCO}_{2}$ (test) is the amount of $\mathrm{CO}_{2}$ evolved in each vial containing tested material and $\mathrm{mCO}_{2}$ (control) is the amount of $\mathrm{CO}_{2}$ evolved in the blank test. 


\section{Results and discussion}

\subsection{Natural seawater ageing}

\subsubsection{Weight loss measurement}

Figure 3 shows the weight loss of the film as a function of immersion time in natural seawater. Two different trends are observed. During the first months of immersion until 120 days, the weight loss increases slowly and progressively and reaches about $11 \%$ after 120 days' immersion. After this time, weight loss suddenly increases and seems to follow an exponential change. The percentage of weight loss after 180 days is about $36 \%$. Some examples in the literature show that the weight loss is often more important than the experimental values. For example, Tsuji et al. [24] found on thin samples $(50 \mu \mathrm{m})$ a weight loss of $60 \%$ after only 5 weeks in natural seawater. Rutkowska et al. [25] also observed a weight of loss of $60 \%$ after an immersion of 6 weeks in seawater but on a thicker sample (115 $\mu \mathrm{m})$. Other authors have found similar percentage losses $(40 \%)$ for a comparable immersion time (160 days) but the thickness of those samples was greater $(800 \mu \mathrm{m})$ [26]. Such variation may be due to difference in initial molecular weight, or in site chosen for the study: seawater temperature, seawater composition like microorganisms population...

Figure 4 shows the macroscopic photographs of the unaged film and of the film evolution after immersion. After 6 months of immersion, the film is degraded on both surfaces exposed to seawater (Figure 4b), and was then affected on the bottom edge. After 9 months of immersion, the PHBV film is substantially disintegrated (Figure 4c) and this image confirms the second trend observed on the Figure 3 with an exponential degradation.

\subsubsection{Surface roughness}

SEM observations on the PHBV are presented in Figure 5 and correspond to the surface and the fracture surfaces of the unaged and aged PHBV film at different times: 60, 120 and 180 days immersed in natural seawater. Unaged PHBV film shows a homogeneous and uniform surface. During ageing, considerable changes occur with the growth of irregularities on the sample surface. Tiny holes appear after 120 days and become larger and deeper after 180 days. Considering the sample fractures, the bulk of the PHBV film retained the same 
appearance whereas a significant reduction of the thickness can be observed after 180 days (Figure 5-4b). The degradation occurred at the surface of the PHBV films and the film thickness regularly decreased with time from the initial time for which it was equal to about $200 \mu \mathrm{m}$ to the final time when it was about $90 \mu \mathrm{m}$. This latter corresponds to the edge thickness of the film presented on Figure $4 b$.

These results are in agreement with the weight loss measurements and they show that the degradation mechanism initially occurs from the surface, with no appreciable change inside the films as for example a typical hydrolytic degradation of PLA [27,28]. According to the literature, the PHBV degradation by an erosion mechanism is attributed to an enzymatic degradation $[10,15]$. Moreover, the enzymatic degradation of PHA is a heterogeneous surface reaction, confirmed by the SEM observations.

\subsubsection{Thermal properties}

The modifications to polymer morphology due to the degradation were revealed by DSC analysis. Table 2 summarizes the thermal properties of PHBV films after 180 days of immersion in natural seawater. A decrease in the melting temperatures was observed after both first and second scans and can be explained by a decrease of polymer chain length.

An increase of $20 \%$ of the crystallinity was also detected in both cases and may be due to several reasons. The rate of enzymatic degradation of PHBV chains in the amorphous state is faster than that of the chains in a crystalline state [29], which necessarily implies an increase of the crystallinity by microstructural changes. Moreover, considering an enzymatic erosion, Sudesh et al. [30] suggested that the active site of PHA depolymerases predominantly break polymer chains in an amorphous phase and subsequently eroded crystalline phase. Shorter chains have higher mobility and they can reorganize themselves, facilitated by the rubbery state of the polymer, leading to an increase of the crystallinity index.

\subsubsection{Molecular weight analysis}

Changes in molecular weight of PHBV films and polydispersity index (PI) are presented in Table 3. During the marine immersion, both number average molecular weight $\left(\bar{M}_{\mathrm{n}}\right)$ and weight average molecular weight $\left(\bar{M}_{\mathrm{w}}\right)$ progressively decrease to reach $30 \%$ of loss after 180 days of immersion in natural seawater. Polydispersity Index also decreases slightly from 1.7 
to 1.5 . Volova et al. [26] observed a $\bar{M}_{\mathrm{w}}$ decrease of $15 \%$ after 160 days of ageing with a constant PI. Moreover, $30 \%$ of $\bar{M}_{\mathrm{w}}$ loss has already been observed on thicker samples without any influence on mechanical properties [20] and only a small decrease of the melting temperature was revealed by the second DSC scan, as detected in this study. The results show that the chain breakages caused by hydrolytic degradation are not the most important mechanism in the degradation of PHBV films, but are mainly due to other phenomena as an enzymatic activity on the surface. Some authors suggest that the slight decrease in molecular weights can be associated with the decrease of the sample weight and could be due to the release of oligomers in water $[31,32]$.

This first part of this paper has focussed on the degradation of PHBV films in natural seawater. The weight loss, the regular decrease of the film thickness and the slow change of molecular weights of the residual samples are observed. Degradation appears as a heterogeneous phenomenon on the surface of the film but the origin is not clearly identified. For this reason in the second part of the paper, another parameter as the biodegradation of PHBV in marine environment is studied.

\subsection{Biodegradation test in marine environment}

\subsubsection{Solid inoculum: foreshore sand}

Figure 6a presents the evolution of the biodegradation of PHBV and cellulose as a function of incubation time in foreshore sand.

According to the experimental results, curves were basically smoothed with a defined model to predict biodegradation profiles and life times of the materials [33]. A single sigmoid, as obtained for the PHBV biodegradation curve, is smoothed with Hill model unlike the cellulose biodegradation curve, which has the form of a double sigmoid (Figure 6a), is here smoothed by the Boltzmann equation. The obtained fitting curves are shown together with the experimental data and the fitting parameters and the calculated half-life times, as well as the maximal biodegradation rates, are given in the Table 4 .

The biodegradation rate of PHBV gradually increases following incubation time even if a slight decrease of the slope appears around 200 days which corresponds to the loss of bacterial activity (figure 6b). After 600 days of incubation, the biodegradation of the cellulose reaches $97 \%$ (with a theoretical biodegradation degree at $100 \%$ for a 690 days plateau), 
against $80 \%$ for PHBV (with a theoretical plateau at 100\% from 1690 days). According to standard NF U52-001, the biodegradation rate for cellulose material must exceed $70 \%$ after 6 months and the difference for tested material does not exceed 20\% [22]. Even if the biodegradation kinetics are slower than the validity criteria of the standard, these results confirm that PHBV is almost completely biodegradable in foreshore sand after 600 days. They also reveal that oligomers produced from the PHBV degradation are metabolized by the micro-organisms in this foreshore sand environment.

Microbial activity trend (Figure 6b) can be explained by a modification of the microbial parameters of the eco-system. It can be assumed that a decrease in the microbial population density is caused by a partial death, with time, of the different micro-organisms responsible for the PHBV biodegradation.

\subsubsection{Solid liquid inoculum: sand and seawater}

Some biodegradation tests were carried out in a solid / liquid medium containing foreshore sand and seawater, considered as a typical natural environment [34]. Considering the Figure $7 \mathrm{a}$, the evolution of the biodegradation degree plotted as a function of incubation time highlights a faster biodegradation kinetic compared to solid inoculum. Indeed, in this incubation medium degradation ratio reaches $90 \%$ after only 210 days against $80 \%$ after 600 days on the sand alone. Therefore, the microorganisms naturally present in the seawater promote PHBV biodegradation after a short delay period, explained by the time necessary for micro-organisms to colonize and to grow at the PHBV surface.

This short delay period is also observed at the macroscopic scale on the weight loss following of the PHBV film and can explained the specific shape of the curve (Figure 3), already observed in the literature by Volova et al. [26]. The film degradation is therefore managed by an enzymatic degradation which is a heterogeneous surface reaction, confirmed by the SEM observations. This process, whatever the shape of the sample, takes place in the presence of PHA depolymerase involving two steps: the first step involves the adsorption of the enzymes on the surface by the binding domain of the enzymes and the second step involves the enzymatic cleavage of polymer chains by the active sites of the enzymes [35]. The enzymatic degradation is obviously influenced by the temperature of the environment and by the chemical and biological parameters, which are related to the season and water temperature. In 
fact, the study began in spring (in March) and the average seawater temperature is about $10^{\circ} \mathrm{C}$ in the harbor. The type or the amount of microorganisms can be different and their activity can be slowed down at low temperature and accelerated by the higher temperatures of the seawater in summer (about $20^{\circ} \mathrm{C}$ in August). The weight loss kinetic depends on all these parameters, confirmed by the variation observed in the literature (presented in the part 3.1.1).

Considering the biodegradation test in solid / liquid inoculum, the first derivative of the Boltzmann equation (Table 4) allow two peaks of microbial activity to be observed (Figure 7b) which correspond to the two sigmoids observed in Figure 7a. The microbial activity initially increases to reach a first maximum at 40 days. Then, there is a significant slowdown in the biodegradation kinetics between 40 and 60 days of incubation. The microbial activity starts again after 60 days to reach a second maximum after 120 days. In the last part of the test between 120 and 220 days, the microbial activity progressively decreases. This irregular variation in the microbial activity may be due several bacteria populations, naturally existing in natural seawater, which are able, consecutively, to metabolize PHBV fragments.

\subsubsection{Liquid inoculum: seawater loaded}

Finally, biodegradation tests were carried out in seawater inoculum with two concentrations of biofilm (5 and 50\%). In this case, the bacterial populations were more abundant than two previous biodegradation tests with $1.3010^{5} \mathrm{CFU} / \mathrm{mL}$ and $1.1410^{6} \mathrm{CFU} / \mathrm{mL}$, for the inoculum containing 5 and $50 \%$ of biofilm, respectively.

Figure 8a shows a comparison between the biodegradation evolutions as a function of the incubation time. Fitting parameters are presented in Table 5.

In the first part of the test, biodegradation kinetics are slightly faster for the inoculum containing $50 \%$ of biofilm compared to $5 \%$ counterparts. However, after 100 days of incubation, the opposite trend is observed. The PHBV in the inoculum containing 5\% of biofilm (95/5) undergoes a faster biodegradation and reaches 97\% biodegradation after 200 days incubation compared to $90 \%$ after 300 days for the $50 \%$. The peak of microbial activity (Figure 8b) appears earlier in the case of the 50/50 mixture and explains the slower biodegradation in the long term, associated with an increase of the bacterial mortality in the inoculum. 
The bacterial activity peak is reached 20 days earlier when the concentration of biofilm is $50 \%$. Nevertheless, the maximum activity level and the trend of the curves are quite similar in the two cases studied (Figure 8b).

These results indicate that the presence of higher concentrations of bacteria does not exert a great influence on biodegradation kinetics. As previously explained, parameters such as microbial population seem to be more relevant [36]. Another phenomenon, already observed in the literature [37], is a threshold of bacterial concentration beyond which the maximum rates of enzymatic degradation are reached. Difficulty to hydrolyze PHBV chains due to complete covering of enzymes and this no active site available could be assumed. As a consequence, excess amounts of enzyme are not essential for completely degrading PHBV and a threshold in micro-organism concentration exists beyond which biodegradation kinetic are longer affected.

These different tests reveal that the inoculum composition strongly influences the biodegradation kinetic. In liquid environment containing seawater, the biodegradation kinetic is faster than in solid inoculum containing sand. This study highlights and confirms an entire bioassimilation of the PHBV film in natural environment thanks to the bacterial attacks on the surface. As recently published [38], the ageing of PHBV was also studied in distilled water and the results indicated that no surface erosion was detected in the absence of bacteria and / or microorganisms. The PHBV biodegradation in natural environments is therefore initiated by the enzymatic hydrolysis reaction with PHA-degrading enzymes. There are then many extracellular PHA depolymerases since PHA-degrading micro-organisms are distributed throughout nearly all terrestrial and aquatic ecosystems [10,18]. This assumption remains nevertheless to be confirmed by identifying the kinds of PHA-degrading micro-organisms at the different stages of the biodegradation.

\section{Conclusions}

The degradation and the biodegradation of PHBV, a biobased and biodegradable polymer, were studied in a marine environment. In a current context of waste reduction, it is essential to understand the degradation rate of PHBV and more generally the control of the end of life of polymers placed on the market is an urgent necessity. 
The first part of the study concerned the natural ageing of PHBV film immerged in seawater. Films aged under natural conditions showed a large loss of weight after 180 days' immersion, confirmed by SEM images with significant surface erosion and a decrease of the sample thickness. After only 9 months in natural seawater immersion, the film was completely disintegrated.

In the second part of the study, the biodegradation of the PHBV was examined using respirometric tests, in different incubation environments. Tests were first carried out in solid inoculum on foreshore sand, then in a solid / liquid inoculum composed on a blend of sand and seawater. A third series of tests was initiated in a liquid inoculum corresponding to seawater in the presence of different amounts of biofilm.

The PHBV is biodegradable in a marine environment at $25^{\circ} \mathrm{C}$, regardless of the incubation medium studied. Some marine microorganisms such as bacteria excrete extracellular PHBV depolymerases that hydrolyze polyester chains and the resulting products are metabolized into the cells and utilized as nutriments. However, the biodegradation kinetics are dependent on the inoculum. Indeed, in foreshore sand, biodegradation kinetics are slower than in seawater but the degree of biodegradation achieved confirmed that PHBV powder is biodegraded in a maximum of 600 days. In the case of the solid/liquid inoculum, the presence of water in the polymer is a promoting factor for a PHBV bioassimilation process [39] which could explain the slower kinetics of the tests conducted in the solid state. The surface contact between micro-organisms and PHBV is greatly improved in the presence of a liquid phase accentuating the degradation kinetics. The degradation of PHBV in seawater may also involve a simple hydrolytic process in addition to an enzymatic degradation. Depending on the experimental conditions, the hydrolytic degradation process could significantly contribute to the degradation of PHBV in the marine environment. Moreover, a significant result concerns the bacterial concentration used in the tests. A threshold was revealed for which the enzymatic degradation rate reaches a maximum and after that, the biodegradation phenomenon is no longer influenced by the bacteria content.

Another important point is the representativeness of these tests carried out in real marine environments. The incubation environments envisaged in this study constitute ecosystems extremely rich in numerous bacteria which do not represent a specific family of previously isolated bacteria. Finally, the diversity of microorganisms associated with these different stages of biodegradation is not yet completely characterized but this is being further explored 
in order to better understand and predict the mechanisms and kinetics of PHBV biodegradation in natural marine environments.

\section{Acknowledgements}

The authors thank the SERPBIO association for financial support and the Aquastream company for the donation of the biofilm collected on the breeding fish tank. The authors are also pleased to express their grateful acknowledgements to Anthony Magueresse, Dr. Patrick Loulergue and Dr. Jean-Luc Audic for their help in the experimental work, Yves-Marie Corre and Pierre-Yves Le Gac (IFREMER) for helpful comments.

\section{References}

[1] Pichel WG, Churnside JH, Veenstra TS, Foley DG, Friedman KS, Brainard RE. Marine debris collects within the North Pacific Subtropical Convergence Zone. Mar Pollut Bull 2007;54:1207-11. doi:10.1016/j.marpolbul.2007.04.010.

[2] Barnes DKA, Galgani F, Thompson RC, Barlaz M. Accumulation and fragmentation of plastic debris in global environments. Philos Trans R Soc B Biol Sci 2009;364:1985-98. doi:10.1098/rstb.2008.0205.

[3] Barnes DKA, Walters A, Gonçalves L. Macroplastics at sea around Antarctica. Mar Environ Res 2010;70:250-2. doi:10.1016/j.marenvres.2010.05.006.

[4] Rios LM, Moore C, Jones PR. Persistent organic pollutants carried by synthetic polymers in the ocean environment. Mar Pollut Bull 2007;54:1230-7. doi:10.1016/j.marpolbul.2007.03.022.

[5] Ryan PG. Seabirds indicate changes in the composition of plastic litter in the Atlantic and south-western Indian Oceans. Mar Pollut Bull 2008;56:1406-9. doi:10.1016/j.marpolbul.2008.05.004.

[6] Avery-Gomm S, O’Hara PD, Kleine L, Bowes V, Wilson LK, Barry KL. Northern fulmars as biological monitors of trends of plastic pollution in the eastern North Pacific. Mar Pollut Bull 2012;64:1776-81. doi:10.1016/j.marpolbul.2012.04.017.

[7] Thompson RC, Olsen Y, Mitchell RP, Davis A, Rowland SJ, John AWG, et al. Lost at Sea: Where Is All the Plastic? Science 2004;304:838-838. doi:10.1126/science.1094559.

[8] Andrady AL. Microplastics in the marine environment. Mar Pollut Bull 2011;62:1596605. doi:10.1016/j.marpolbul.2011.05.030.

[9] Alexander M. Biodegradation of chemicals of environmental concern. Science 1981;211:132-8. doi:10.1126/science.7444456.

[10] Sudesh K, Abe H, Doi Y. Synthesis, structure and properties of polyhydroxyalkanoates: biological polyesters. Prog Polym Sci 2000;25:1503-55. doi:10.1016/S00796700(00)00035-6.

[11] Avella M, Rota GL, Martuscelli E, Raimo M, Sadocco P, Elegir G, et al. Poly(3hydroxybutyrate-co-3-hydroxyvalerate) and wheat straw fibre composites: thermal, mechanical properties and biodegradation behaviour. J Mater Sci 2000;35:829-36. doi:10.1023/A:1004773603516. 
[12] Pagga U, Beimborn DB, Boelens J, De Wilde B. Determination of the aerobic biodegradability of polymeric material in a laboratory controlled composting test. Chemosphere 1995;31:4475-87. doi:10.1016/0045-6535(95)00326-4.

[13] Saadi Z, Cesar G, Bewa H, Benguigui L. Fungal Degradation of Poly(Butylene AdipateCo-Terephthalate) in Soil and in Compost. J Polym Environ 2013;21:893-901. doi:10.1007/s10924-013-0582-2.

[14] Mergaert J, Anderson C, Wouters A, Swings J. Microbial degradation of poly(3hydroxybutyrate) and poly(3-hydroxybutyrate-co-3-hydroxyvalerate) in compost. J Polym Environ 1994;2:177-83. doi:10.1007/BF02067443.

[15] Weng Y-X, Wang Y, Wang X-L, Wang Y-Z. Biodegradation behavior of PHBV films in a pilot-scale composting condition. Polym Test 2010;29:579-87. doi:10.1016/j.polymertesting.2010.04.002.

[16] Sang B-I, Hori K, Tanji Y, Unno H. Fungal contribution to in situ biodegradation of poly(3-hydroxybutyrate-co-3-hydroxyvalerate) film in soil. Appl Microbiol Biotechnol 2002;58:241-7. doi:10.1007/s00253-001-0884-5.

[17] Batista KC, Silva D a. K, Coelho L a. F, Pezzin SH, Pezzin APT. Soil Biodegradation of PHBV/Peach Palm Particles Biocomposites. J Polym Environ 2010;18:346-54. doi:10.1007/s10924-010-0238-4.

[18] Doi Y, Kasuya K, Abe H, Koyama N, Shin-ichi I, Koichi T, et al. Evaluation of biodegradabilities of biosynthetic and chemosynthetic polyesters in river water. Polym Degrad Stab 1996;51:281-6. doi:10.1016/0141-3910(95)00178-6.

[19] Kasuya K, Takagi K, Ishiwatari S, Yoshida Y, Doi Y. Biodegradabilities of various aliphatic polyesters in natural waters. Polym Degrad Stab 1998;59:327-32. doi:10.1016/S0141-3910(97)00155-9.

[20] Deroiné M, Le Duigou A, Corre Y-M, Le Gac P-Y, Davies P, César G, et al. Seawater accelerated ageing of poly(3-hydroxybutyrate-co-3-hydroxyvalerate). Polym Degrad Stab 2014;105:237-47. doi:10.1016/j.polymdegradstab.2014.04.026.

[21] Corre Y-M, Bruzaud S, Audic J-L, Grohens Y. Morphology and functional properties of commercial polyhydroxyalkanoates: A comprehensive and comparative study. Polym Test 2012;31:226-35. doi:10.1016/j.polymertesting.2011.11.002.

[22] AFNOR. NF U52-001 : Biodegradable materials for use in agriculture and horticulture Mulching products - Requirements and test methods. 2005.

[23] Barham PJ, Keller A, Otun EL, Holmes PA. Crystallization and morphology of a bacterial thermoplastic: poly-3-hydroxybutyrate. J Mater Sci 1984;19:2781-94. doi:10.1007/BF01026954.

[24] Tsuji H, Suzuyoshi K. Environmental degradation of biodegradable polyesters 2. Poly( $\varepsilon$ caprolactone), poly[(R)-3-hydroxybutyrate], and poly(L-lactide) films in natural dynamic seawater. Polym Degrad Stab 2002;75:357-65. doi:10.1016/S01413910(01)00239-7.

[25] Rutkowska M, Krasowska K, Heimowska A, Adamus G, Sobota M, Musioł M, et al. Environmental Degradation of Blends of Atactic Poly[(R,S)-3-hydroxybutyrate] with Natural PHBV in Baltic Sea Water and Compost with Activated Sludge. J Polym Environ 2008;16:183-91. doi:10.1007/s10924-008-0100-0.

[26] Volova TG, Boyandin AN, Vasiliev AD, Karpov VA, Prudnikova SV, Mishukova OV, et al. Biodegradation of polyhydroxyalkanoates (PHAs) in tropical coastal waters and identification of PHA-degrading bacteria. Polym Degrad Stab 2010;95:2350-9. doi:10.1016/j.polymdegradstab.2010.08.023.

[27] Luo YB, Wang X-L, Wang Y-Z. Effect of TiO2 nanoparticles on the long-term hydrolytic degradation behavior of PLA. Polym Degrad Stab 2012;97:721-8. doi:10.1016/j.polymdegradstab.2012.02.011. 
[28] Deroiné M, Le Duigou A, Corre Y-M, Le Gac P-Y, Davies P, César G, et al. Accelerated ageing of polylactide in aqueous environments: Comparative study between distilled water and seawater. Polym Degrad Stab 2014;108:319-29. doi:10.1016/j.polymdegradstab.2014.01.020.

[29] Kumagai Y, Kanesawa Y, Doi Y. Enzymatic degradation of microbial poly(3hydroxybutyrate) films. Makromol Chem 1992;193:53-7. doi:10.1002/macp.1992.021930105.

[30] Sudesh K, Abe H. Practical Guide to Microbial Polyhydroxyalkanoates. iSmithers Rapra Publishing; 2010.

[31] Kim DY, Rhee YH. Biodegradation of microbial and synthetic polyesters by fungi. Appl Microbiol Biotechnol 2003;61:300-8. doi:10.1007/s00253-002-1205-3.

[32] Mergaert J, Swings J. Biodiversity of microorganisms that degrade bacterial and synthetic polyesters. J Ind Microbiol 1996;17:463-9. doi:10.1007/BF01574777.

[33] Domenek S, Feuilloley P, Gratraud J, Morel M-H, Guilbert S. Biodegradability of wheat gluten based bioplastics. Chemosphere 2004;54:551-9. doi:10.1016/S00456535(03)00760-4.

[34] Innocenti FD. Laboratory test methods to determine the degradation of plastics in marine environmental conditions. Front Microbiotechnology Ecotoxicol Bioremediation 2012;3:225. doi:10.3389/fmicb.2012.00225.

[35] Numata K, Abe H, Doi Y. Enzymatic processes for biodegradation of poly(hydroxyalkanoate)s crystals. Can J Chem 2008;86:471-83. doi:10.1139/v08-004.

[36] Taguchi S, Iwata T, Abe H, Doi Y. 9.09 - Poly(hydroxyalkanoate)s. In: Matyjaszewski K, Möller M, editors. Polym. Sci. Compr. Ref., Amsterdam: Elsevier; 2012, p. 157-82.

[37] Mukai K, Yamada K, Doi Y. Enzymatic degradation of poly(hydroxyalkanoates) by a marine bacterium. Polym Degrad Stab 1993;41:85-91. doi:10.1016/01413910(93)90066-R.

[38] Deroiné M, Le Duigou A, Corre Y-M, Le Gac P-Y, Davies P, César G, et al. Accelerated ageing and lifetime prediction of poly(3-hydroxybutyrate-co-3-hydroxyvalerate) in distilled water. Polym Test 2014;39:70-8. doi:10.1016/j.polymertesting.2014.07.018.

[39] Hakkarainen M. Aliphatic Polyesters: Abiotic and Biotic Degradation and Degradation Products. Degradable Aliphatic Polyest., Springer Berlin Heidelberg; 2002, p. 113-38. 


\section{Table 1}

Hydrochemical parameters of seawater.

\begin{tabular}{lcccc}
\hline & $\begin{array}{c}\text { Temperature of } \\
\text { water }^{\mathrm{a}}\left({ }^{\circ} \mathrm{C}\right)\end{array}$ & $\mathrm{pH}^{\mathrm{a}}$ & $\begin{array}{c}\text { Salinity }^{\mathrm{b}} \\
(\mathrm{ppm})\end{array}$ & $\begin{array}{c}\text { Oxygen }^{\mathrm{b}} \\
(\mathrm{mg} / \mathrm{mL})\end{array}$ \\
\hline March 2012 & $10.9 \pm 0.6$ & 8.21 & 34.8 & 6.5 \\
April & $11.3 \pm 0.3$ & 7.9 & 34.6 & 7.4 \\
May & $13.5 \pm 0.1$ & 8.06 & 35 & 6.2 \\
June & $15 \pm 0.1$ & 8.0 & 34.9 & 6.7 \\
July & $18.4 \pm 1.0$ & 7.98 & 34.2 & 6.2 \\
August & $19.8 \pm 0.8$ & 8.02 & 34.7 & 6.3 \\
September & $17.2 \pm 0.2$ & 7.99 & 34.7 & 5.3 \\
\hline
\end{tabular}

${ }^{a}$ Personal data

${ }^{\mathrm{b}}$ IFREMER buoy data

\section{Table 2}

Evolution of the thermal transitions of PHBV films aged during 6 months in natural seawater.

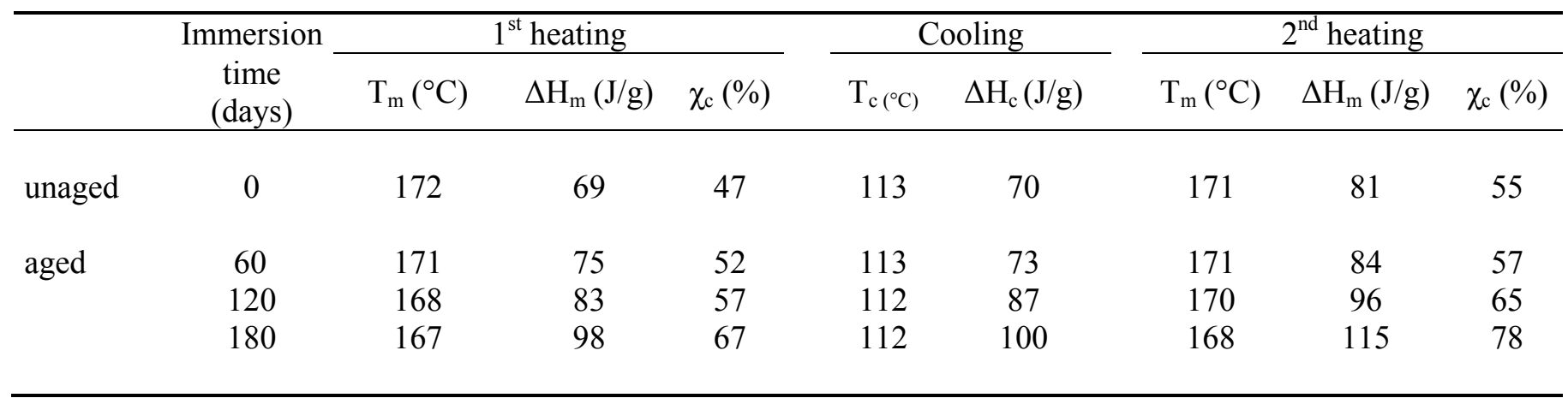

Table 3

Evolution of number-average molecular weight $\left(\bar{M}_{\mathrm{n}}\right)$, weight-average molecular weight $\left(\bar{M}_{\mathrm{w}}\right)$ and polydispersity index $\left(\mathrm{M}_{\mathrm{n}} / \mathrm{M}_{\mathrm{w}}\right)$ of PHBV samples aged 6 months in natural seawater.

\begin{tabular}{lcccc}
\hline & & $\overline{\mathrm{M}}_{\mathrm{n}}\left(\mathrm{g} \cdot \mathrm{mol}^{-1}\right)$ & $\overline{\mathrm{M}}_{\mathrm{w}}\left(\mathrm{g} \cdot \mathrm{mol}^{-1}\right)$ & $\mathrm{M}_{\mathrm{n}} / \mathrm{M}_{\mathrm{w}}$ \\
\hline unaged & 0 & 259000 & 455000 & 1.7 \\
\multirow{2}{*}{ aged } & 60 & 220000 & 450000 & 2.1 \\
& 120 & 195000 & 360000 & 1.6 \\
& 180 & 180000 & 320000 & 1.5 \\
\hline
\end{tabular}




\section{Table 4}

Hill and Boltzman models used to predict the biodegradation profiles of PHBV and cellulose in the respirometric tests and fitting parameter values.

\section{Test in foreshore sand inoculum Test in seawater and sand inoculum}

at $25^{\circ} \mathrm{C}$ at $25^{\circ} \mathrm{C}$

\section{PHBV material}

Hill equation:

$$
\begin{aligned}
\mathrm{y} & =\mathrm{ax}^{\mathrm{b}} /\left(\mathrm{c}^{\mathrm{b}}+\mathrm{x}^{\mathrm{b}}\right) \\
\mathrm{a} & =103.996 \\
\mathrm{~b} & =1.952 \\
\mathrm{c} & =323.935 \\
\mathrm{R}^{2} & =0.998
\end{aligned}
$$

\begin{tabular}{|c|c|}
\hline \multicolumn{2}{|c|}{ Boltzman equation : $y=A_{1}+\left(A_{2}-A_{1}\right)\left[p /\left(1+10^{\left((x 1-x)^{*} h 1\right)}\right)+(1-p\right.$} \\
\hline $\mathrm{A}_{1}=0.000$ & $\mathrm{~A}_{1}=0.000$ \\
\hline $\mathrm{A}_{2}=100.435$ & $\mathrm{~A}_{2}=48.941$ \\
\hline $\mathrm{h}_{1}=0.006$ & $\mathrm{~h}_{1}=0.089$ \\
\hline $\mathrm{h}_{2}=0.017$ & $\mathrm{~h}_{2}=0.023$ \\
\hline $\mathrm{p}=0.785$ & $\mathrm{p}=0.286$ \\
\hline $\mathrm{x}_{1}=285.403$ & $\mathrm{x}_{1}=35.309$ \\
\hline $\mathrm{x}_{2}=543.681$ & $\mathrm{x}_{2}=151.471$ \\
\hline $\mathrm{R}^{2}=0.999$ & $\mathrm{R}^{2}=0.994$ \\
\hline
\end{tabular}

Boltzman equation :

$$
\begin{aligned}
\mathrm{y}=\mathrm{A}_{1}+\left(\mathrm{A}_{2}-\mathrm{A}_{1}\right)\left[\mathrm{p} /\left(1+10^{\left((\mathrm{x} 1-\mathrm{x})^{*} \mathrm{~h} 1\right)}\right)+(1-\mathrm{p}) /\left(1+10^{\left((\mathrm{x} 2-\mathrm{x})^{*} \mathrm{~h} 2\right)}\right)\right] \\
\mathrm{A}_{1}=0.000 \\
\mathrm{~A}_{2}=91.359 \\
\mathrm{~h}_{1}=0.059 \\
\mathrm{~h}_{2}=0.018 \\
\mathrm{p}=0.126 \\
\mathrm{x}_{1}=35.797 \\
\mathrm{x}_{2}=124.479 \\
\mathrm{R}^{2}=0.998
\end{aligned}
$$

\section{Cellulose material}

$\mathrm{h}_{1}$ : Slope of the $1^{\text {st }}$ sigmoid

$\mathrm{h}_{2}$ : Slope of the $2^{\text {nd }}$ sigmoid

$\mathrm{p}$ : Proportion occupied by the first part of the curve

$\mathrm{x}_{1}$ : Half-life time of the $1^{\text {st }}$ sigmoid (days)

$\mathrm{x}_{2}$ : Half-life time of the $2^{\text {nd }}$ sigmoid (days)

$\mathrm{R}^{2}$ : Correlation coefficient of the model 


\section{Table 5}

Hill models to predict the biodegradation profiles of PHBV in the respirometric test with different percentage of biofilm and fitting parameter values.

\begin{tabular}{|c|c|}
\hline $\begin{array}{l}\text { Test with 50-50 inoculum } \\
\text { at } 25^{\circ} \mathrm{C}\end{array}$ & $\begin{array}{l}\text { Test with 5-95 inoculum } \\
\text { at } 25^{\circ} \mathrm{C}\end{array}$ \\
\hline \multicolumn{2}{|c|}{$\frac{P H B V \text { material }}{\text { Hill equation }: \mathrm{y}}=\mathrm{ax}^{\mathrm{b}} /\left(\mathrm{c}^{\mathrm{b}}+\mathrm{x}^{\mathrm{b}}\right)$} \\
\hline$a=107.600$ & $a=123.516$ \\
\hline $\mathrm{b}=1.362$ & $b=1.615$ \\
\hline $\mathrm{c}=88.409$ & $c=102.374$ \\
\hline $\mathrm{R}^{2}=0.998$ & $\mathrm{R}^{2}=0.996$ \\
\hline
\end{tabular}






a

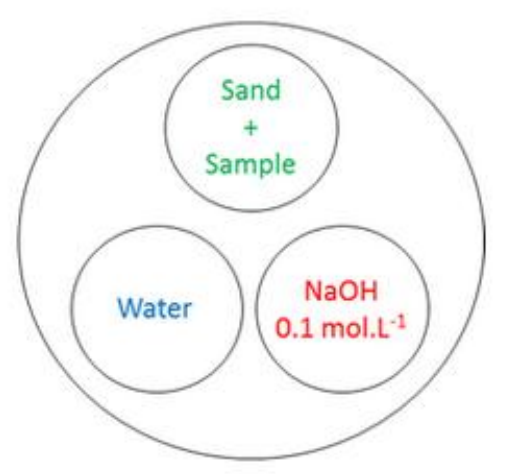

b

Fig. 1

Schema of biodegradation test at solid state in foreshore sand: $\mathbf{a}$ front view and $\mathbf{b}$ top view



Fig. 2

Schema of biodegradation test at solid/liquid state and at liquid state in marine environment 


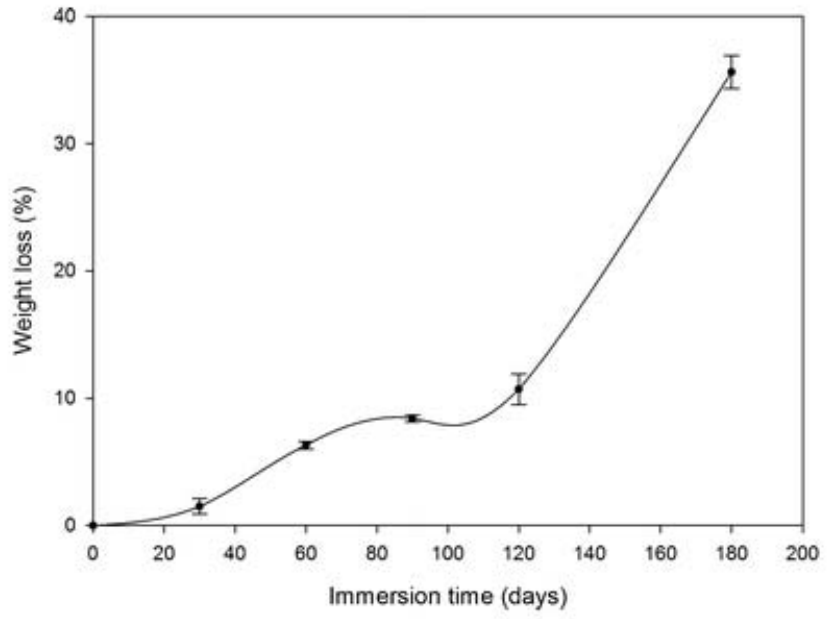

Fig. 3

Evolution of weight loss as a function of immersion time for the PHBV film aged in natural condition (and error bars correspond to standard deviations) 

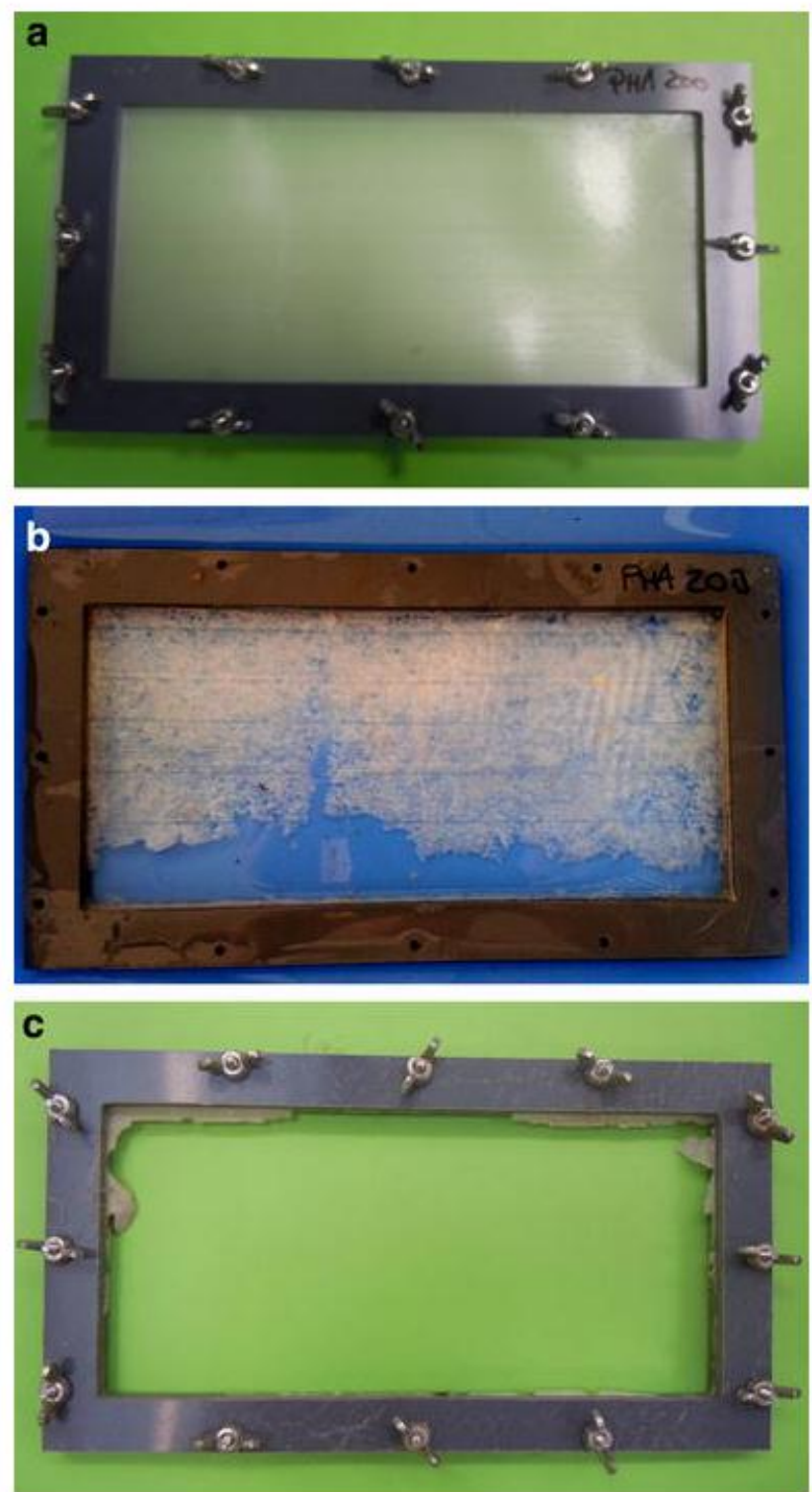

Fig. 4

PHBV specimen before (a) and after 6 and 9 months of immersion in natural seawater (b and c respectively) 

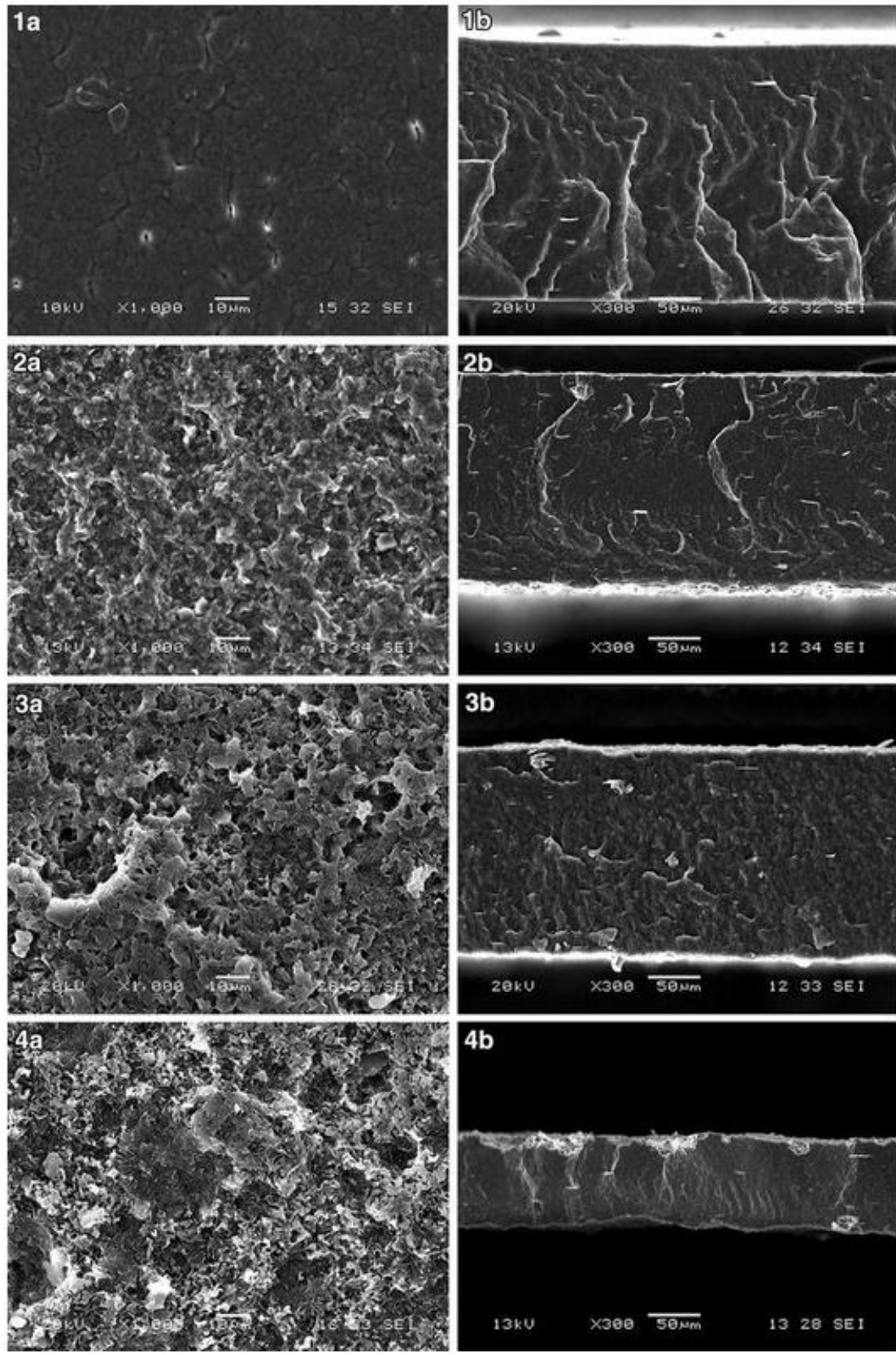

Fig. 5

SEM micrographs of the surface (a) and the fracture (b) of PHBV films unaged (1) and aged in natural seawater after 60 days (2), 120 days (3) and 180 days (4) 

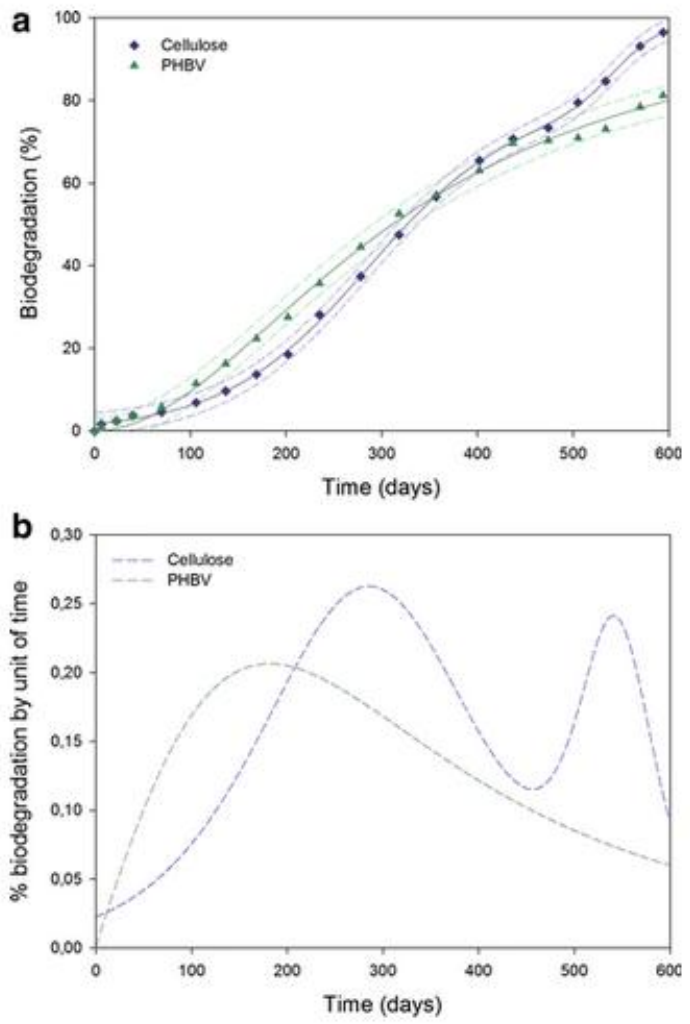

Fig. 6

Macroscopic photographs of unaged film of PHBV and aged after 180 days in natural seawater 

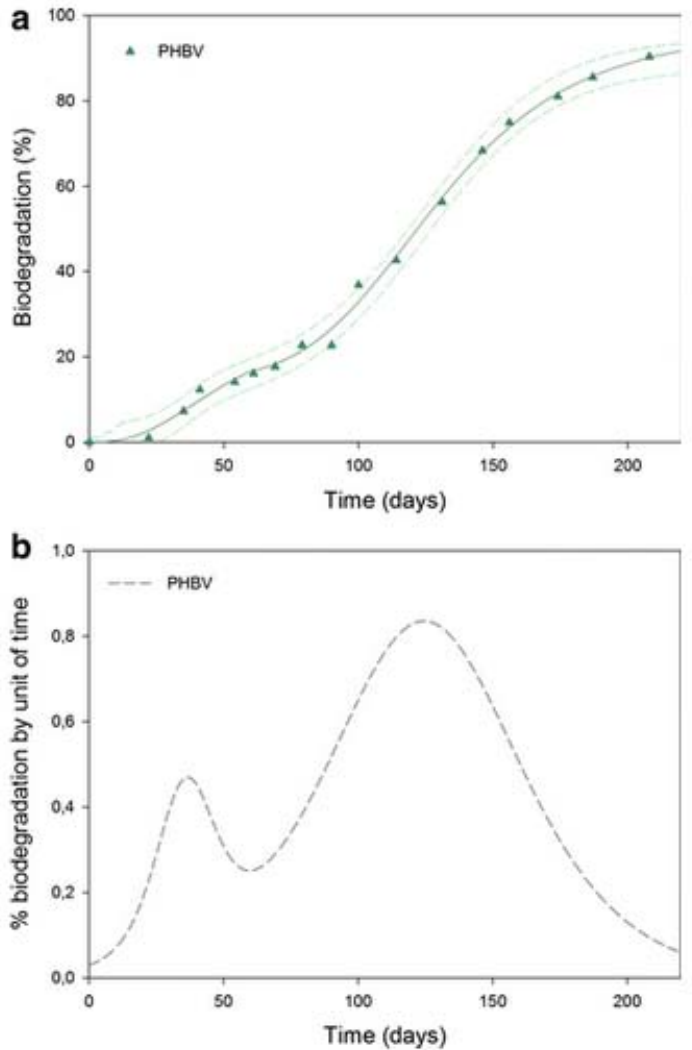

Fig. 7

Biodegradation test of PHBV and cellulose powders in inoculated foreshore sand (the solid line shows the degradation curve, which was calculated with the Hill and Boltzmann model and the short lines correspond to the probability that $95 \%$ of the values are within these intervals) (a) and evolution of the microbial activity

(b) 



Fig. 8

Biodegradation test of PHBV and cellulose powders in inoculated seawater and foreshore sand (the solid line shows the degradation curve, which was calculated with the Boltzmann model and the short lines correspond to the probability that $95 \%$ of the values are within these intervals) (a) and evolution of the microbial activity (b) 